\section{POS0496 YOUNG VERSUS LATE-ONSET RHEUMATOID ARTHRITIS: A PROSPECTIVE 12 MONTH-FOLLOW-UP COHORT STUDY IN AN EARLY ARTHRITIS COHORT}

A. R. Prata $^{1}$, M. Sousa ${ }^{1}$, H. Assunção ${ }^{1}$, L. Saraiva ${ }^{1}$, L. Brites ${ }^{1}$, M. Luis ${ }^{1,2}$, P. Freitas ${ }^{1}$, F. Campos Costa ${ }^{1}$, T. Santiago ${ }^{1,2}$, J. A. P. da Silva ${ }^{1,2}$, C. Duarte ${ }^{1,2}$. ${ }^{1}$ Centro Hospitalar e Universitário de Coimbra, Rheumatology, Coimbra, Portugal; ${ }^{2}$ University of Coimbra, Faculty of Medicine, Coimbra, Portugal

Background: Rheumatoid Arthritis (RA) is a chronic inflammatory arthropathy that can present at any age. Data regarding differences in the clinical course and outcome in Late-Onset Rheumatoid Arthritis (LORA) comparing to Young-Onset RA (YORA) are conflicting. Some studies suggested that LORA may represent a more benign form of RA (1), while others have shown a poorer prognosis in these patients $(2,3)$. Only a few publications have included patients with early disease (3).

Objectives: To compare demographic and clinical features between LORA and YORA patients, and clinical activity at baseline and after 12 months of initial therapy, in patients with early disease.

Methods: We conducted a prospective cohort study of 12 months of follow-up based on an early arthritis clinic. Consecutive patients with early RA - less than 12 months duration - fulfilling ACR/EULAR 2010 and/or ACR 1987 RA classification criteria, were included and classified in LORA (disease onset $\geq 60$ years) and YORA groups. Variables were collected from patients' registries at first appointment after symptoms onset and after 12 months of treatment, according to a treat-to-target strategy. Independent t-test and chi-square test were performed to compare variables between groups.

Results: We included 72 patients (40 (55.6\%) YORA; 32 (44.4\%) LORA), mean age at diagnosis $44.9 \pm 1.78$ and $72.5 \pm 1.34$ years, respectively. In LORA group, the symptoms duration at first observation was shorter $(17.0 \pm 2.26$ vs. $23.8 \pm 2.45$ weeks; $\mathrm{p}=0.046$ ) and rheumatoid factor (RF)/ anti-citrullinated protein antibodies (ACPA) positivity was lower (28.1\% vs $65.0 \%$; $p=0.002$; $31.3 \%$ vs $72.5 \%$; $\mathrm{p}<0.001)$. At baseline, LORA had higher mean number of tender joints $(9.76 \pm 1.29$ vs $6.50 \pm 0.67 ; p=0.021)$, erythrocyte sedimentation rate (ESR) $(45.7 \pm 4.98$ vs. $29.3 \pm 3.74 ; p=0.011)$, C-reactive protein (CRP) $(4.63 \pm 0.91$ vs $2.22 \pm 0.46 ; p=0.022)$ and disease activity using DAS28-3V ( $5.11 \pm 0.28$ vs $4.42 \pm 0.19 ; p=0.046)$, CDAl $(33.7 \pm 3.39$ vs $23.6 \pm 2.18 ; p=0.015)$ and SDAl $(37.4 \pm 3.43$ vs $26.3 \pm 2.57 ; p=0.015)$. At the end of follow-up, there were no statistically significant differences between LORA and YORA groups regarding treatment, disease activity and patient-reported outcomes at 12 months (Table 1).

Table 1. Clinical variables assessment at $\mathbf{1 2}$ months of follow-up.

\begin{tabular}{lccc}
\hline & EORA & YORA & $p$-value \\
\hline Treatment, \% users & & & \\
$\quad$ Corticosteroids & 93.3 & 97.4 & $\mathrm{p}=0.576$ \\
Methotrexate & 76.7 & 74.4 & $\mathrm{p}=0.825$ \\
Hydroxychloroquine & 43.3 & 46.2 & $\mathrm{p}=0.815$ \\
Sulfasalazine & 10.0 & 15.4 & $\mathrm{p}=0.722$ \\
$\quad$ Leflunomide & 3.30 & 5.10 & $\mathrm{p}=1.000$ \\
$\quad$ TNF blockers & 3.30 & 5.10 & $\mathrm{p}=0.717$ \\
DAS28-3V, mean (SD) & $1.99 \pm 0.15$ & $2.22 \pm 0.15$ & $\mathrm{p}=0.286$ \\
SDAl, mean (SD) & $4.64 \pm 1.35$ & $7.68 \pm 1.39$ & $\mathrm{p}=0.128$ \\
CDAl, mean (SD) & $4.15 \pm 1.17$ & $6.56 \pm 1.32$ & $\mathrm{p}=0.180$ \\
Swollen joints, mean (SD) & $1.29 \pm 0.49$ & $1.03 \pm 0.25$ & $\mathrm{p}=0.613$ \\
Tender joints, mean (SD) & $0.32 \pm .13$ & $1.2 \pm \pm 0.53$ & $\mathrm{p}=0.084$ \\
ESR, mean (SD) & $10.6 \pm 1.79$ & $9.43 \pm 1.14$ & $\mathrm{p}=0.585$ \\
CRP, mean (SD) & $0.44 \pm 0.09$ & $0.50 \pm 0.15$ & $\mathrm{p}=0.730$ \\
PtGA, mean (SD) & $21.8 \pm 5.90$ & $29.2 \pm 6.11$ & $\mathrm{p}=0.387$ \\
PhGA, mean (SD) & $10.6 \pm 3.26$ & $13.1 \pm 3.11$ & $\mathrm{p}=0.593$ \\
Pain intensity (VAS), mean (SD) & $20.7 \pm 5.82$ & $32.7 \pm 6.30$ & $\mathrm{p}=0.169$ \\
HAQ, mean (SD) & $0.23 \pm 0.089$ & $0.54 \pm 0.13$ & $\mathrm{p}=0.060$ \\
& & &
\end{tabular}

Legend: DMARD- disease-modifying anti-rheumatic drug; TNF- tumoral necrosis factor; SDAl-simplified disease activity score; CDAl- clinical disease activity score; PtGA/ PhGA patient's/ physician's global assessment of general health; VAS- visual analogic scale; HAQhealth assessment questionnaire.

Conclusion: LORA patients presented with higher disease activity manifested by higher joint counts and laboratory inflammatory markers but lower RF and ACPA positivity proportion. Despite the more aggressive clinical presentation, the clinical and functional outcomes at 12 months were similar between LORA and YORA patients.

REFERENCES

[1] Deal et al. Arthritis Rheum 1985;28(9):987-94.

[2] Arnold et al. Rheumatology (Oxford) 2014; 53:10751086

[3] Romão et al. Semin Arthritis Rheum 2020;0(4):735-743.

Disclosure of Interests: None declared

DOI: 10.1136/annrheumdis-2021-eular.3631

\section{POS0497 \\ A RELIABILITY EXERCISE USING CONSENSUAL DEFINITIONS FOR THE ULTRASONOGRAPHY OF THE SHOULDER IN RHEUMATOID ARTHRITIS}

K. Ben Abdelghani ${ }^{1}$, S. Miladi ${ }^{1}$, I. Mahmoud ${ }^{2}$, H. Ajlani ${ }^{3}$, E. Haddouche ${ }^{4}$ A. Maghraoui ${ }^{5}$, S. Slimani ${ }^{6}$, A. Fazaa ${ }^{1}$, A. Ben Tekaya ${ }^{2}$, L. Abdelmoula ${ }^{2}$, A. Laatar ${ }^{1}$, R. Bahiri ${ }^{7}{ }^{1}$ Université de Tunis El Manar, Mongi Slim Hospital, Rheumatology, Tunis, Tunisia; ${ }^{2}$ Université de Tunis El Manar, Chrles Nicolle Hospital, Rheumatology, Tunis, Tunisia; ${ }^{3}$ El Yasminet Hospital, Ben Arous, Rheumatology, Tunis, Tunisia; ${ }^{4}$ Department of Rheumatology, Ben Aknoun Specialized Hospital in the Musculoskeletal System, Rheumatology, Algers, Algeria; ${ }^{5}$ Rheumatology Private Office, Rheumatology, Rabat, Morocco; ${ }^{6}$ Atlas Clinic of Rheumatology, Rheumatology, Batna, Algeria; ${ }^{7}$ El Ayachi Hospital, $\mathrm{CHU}$ Rabat-Salé, Rheumatology, Rabat, Morocco

Background: Although numerous clinical tests for the diagnosis of painful shoulder are available, differentiating articular from periarticular lesions may be difficult in daily practice. Fortunately, the precise diagnosis of shoulder pain in RA benefited from a reliable imaging modality to detect its exact origin as ultrasonography (US). Objectives: This study aimed to assess the intraobserver and interobserver reliabilities of the ultrasonographic findings for patients with established RA having shoulder pain in a patient-based exercise among maghrebian rheumatologists experts on US

Methods: A total of 7 operators examined 10 patients in 2 rounds independently and blindly of each other.

Each patient underwent a US scanning of the painful shoulder in four sites based on US technical guidelines of the European society of musculoskeletal radiology: long head of Biceps (LHB), subscapularis recess, posterior recess and axillary recess. The presence of a subdeltoid or subcoracoid bursitis or the presence of transfixiant tear of the suprasupinatus were notified if present. Intra and inter-observer reliabilities were calculated.

Results: Intraobserver reliability was excellent for GS synovitis in subscapularis and posterior recesses ( $k=0.91$ for both) and for subcoracoid bursitis ( $k=0.81)$. I was good in case of presence of a subdeltoid bursitis $(k=0.79)$, transfixiant tear of the suprasupinatus ( $k=0.65)$, GS synovitis and effusion in LHB ( $k=0.67$ and 0.6 respectively) and subdeltoid bursitis $(k=0.79)$. Interobserver reliability was good for PD for LHB signals searched longitudinally $(\mathrm{k}=0.78)$ and transversally ( $k=0.78)$. It was moderate for $G S$ for LHB synovitis $(k=0.55)$. Interobserver agreement was poor for effusion and GS synovitis for subscapularis, posterior and axillary recesses. It was very poor and/or absent for PD signals in these recesses. Conclusion: US is a reliable imaging tool for shoulder in RA especially with regard to LHB effusion, GS and PD synovitis. Interobserver reliability of subscapularis, posterior and axillary recesses could be optimized by standardization of sites to assess. REFERENCES:

[1] Bruyn G a. W, Naredo E, Möller I, Moragues C, Garrido J, de Bock GH, et al. Reliability of ultrasonography in detecting shoulder disease in patients with rheumatoid arthritis. Ann Rheum Dis 2009;68:357-61.

Disclosure of Interests: None declared

DOI: 10.1136/annrheumdis-2021-eular.3736

\section{POS0498 RELATIONSHIP BETWEEN IMPAIRED MELATONIN SECRETION AND DURATION, RADIOLOGICAL STAGE AND PHYSICAL ACTIVITY OF RHEUMATOID ARTHRITIS}

Y. Sikalo ${ }^{1}$, L. Zhuravlyova ${ }^{1}$, M. Oliinyk ${ }^{1}$, V. Fedorov ${ }^{1} .{ }^{1}$ Kharkiv National Medical University, Internal Medicine No.3 and Endocrinology, Kharkiv, Ukraine

Background: There is a close relationship between the development of severe autoimmune diseases and disorders of the neuroendocrine immune regulation of the body [1]. The role of melatonin as the main mediator of neuroendocrinoimmune interactions in rheumatoid arthritis (RA) remains poorly understood [2] Objectives: The aim of the study was to determine the daily serum melatonin profile of RA patients with different duration of the disease, radiological stage and physical activity.

Methods: The daily serum melatonin profile of patients with active RA ( $n=105$, mean age $49.8 \pm 12.6$ years, $75.5 \%$ of women) was compared with that of healthy subjects from the general population $(n=30)$. In addition, we investigated daily serum melatonin secretion in relation to duration of the disease, radiological progression and physical activity (HAQ). Patients were divided into 4 groups depending on the RA duration (mean $8.4 \pm 6.6$ years): $1^{\text {st }}$ group - up to 2 years $(n=12), 2^{\text {nd }}$ group $-2-5$ years $(n=37)$, $3^{\text {rd }}$ group $-6-10$ years $(n=26), 4^{\text {th }}$ group - more than 10 years $(n=30)$. Depending on the radiological progression, patients were divided into stages: $1^{\text {st }}$ stage $(n=16), 2^{\text {nd }}$ stage $(n=64), 3^{d}$ stage $(n=25)$. Melatonin serum levels was determined by the enzyme immunoassay at 8 and 20 o'clock. For statistical analysis were used the Man - Whitney test and the Spearman rank correlation method. 